\title{
XXVIII. Cyclones of the bay of bengal
}

\section{W.R. Birt}

To cite this article: W.R. Birt (1880) XXVIII. Cyclones of the bay of bengal , Philosophical Magazine Series 5, 9:55, 221-225, DOI: 10.1080/14786448008626827

To link to this article: http://dx.doi.org/10.1080/14786448008626827

曲 Published online: 08 Jun 2010.

Submit your article to this journal

LII Article views: 3

Q View related articles $₫$ 
$\frac{T}{2}$ is substituted for $\mathrm{T}$ and $\frac{\mathrm{P}}{2}$ for $\mathrm{P}$; and then they represent only one half of the motion, while $\mathrm{T}$ signifies the entire duration of a vibration. On the other hand, the trigonometric series given by (31) agrees in substance with the series found by Helmboltz, if', in the latter, $\mathfrak{T}$ is understood as denoting the time of the ascending motion of a single determined point of the string. How this series in Helmholtz's work is obtained does not appear to me to be clearly shown. For, apparently, the letters $x$ and $\mathfrak{I}$ are at one time used for a variable, and then again for a fixed point of the string; and it does not distinctly appear whether the mathematical development rests upon the assumption of the law enunciated in no. 8 as valid for all points of the string, or whether it is presupposed for a single point only. The latter is done by Donkin and Lord Rayleigh. But if the problem is to be determined, not only must $y$ but also $\frac{\partial y}{\partial x}$ be given as a function of $t$ for the one point of the string. This uncertainty asserts itself in tho works mentioned by rendering it necessary, in the determination of $\mathfrak{I}$ as a function of $x$, to go back to the observations.

Freiburg i. B., July 12, 1879.

XXVIII. Cyclones of the Bay of Bengal*. By W. R. BIrT. $T \mathrm{~T}$ is well known that the Bay of Bengal is a very dangerous 1 locality for our East-Indian shipping, especially the head of the Bay in the neighbourhood of Calcutta. The danger principally arises from the cyclones which sweep over the Bay, wrecking ships and raising immense storm-waves exceedingly destructive of human life. Thus in the year 1737, October 7 , three hundred thousand people are stated to have been drowned; more than one hundred years later, in 1876, October 29 to November 1, one hundred thousand people were drowned in Backergunge. In June 1822, ffty thousand people perished by the storm-wave. In the year 1864, October 2 to 5 , forty-eight thousand people were drowned in the Hooghly by the storm-wave; and in 1831, October 31, ten thousand people were drowned by the storm-wave. In the following year, 1832, May 21, between eight and ten thousand people perished by the same agency. The total loss of human life, as recorded in connexion with severe cyclones that swept over the Bay on the dates given above, is no less

* Report of the Madras Cyclone of May 1877, by J. Eliot, Esq, M.A., Meteorological Reporter to the Government of Bengal. Calcutta, 1879. Plit. Mag. S. 5. Vol. 9. No. 55. March $1880 . \quad$ R 
than five hundved and seventeen thousand; and this great number is small compared with the immense number that must have perished in the aggregate number of cyclones that have occurred; consequently any addition to our knowledge of these destructive meteors cannot fail of being interesting to our readers, as well as to navigators and seamen.

\section{Antecedents of Powerful Cyclones.}

The importance of a knowledge of the antecedents of cyclones, especially of such as are attended with great loss of life, cannot be overrated. For an increase of our knowledge in this respect we are indebted to J. Eliot, Esq., M.A., Meteorological Reporter to the Government of Bengal, in his Report on the Madras Cyclone of May 1877. In order clearly to connect the antecedents with the cyclones it is necessary to take into consideration the two transitionperiods :-one, in April or near the latter end of April, between the breaking-up of the north-east monsoon and the establishment of the south-west; the other, in October, succeeding the south-west monsoon and ushering in the north-east monsoon. Mr. Eliot finds that cyclones or revolving storms of great extent and intensity occur only at these periods, while cyclonic disturbances of small intensity are of frequent occurrence during the rainy season or south-west monsoon. During the continuance of each monsoon certain meteorological relations are established over the Bay and the adjoining land-areas; and when a change from one monsoon to the other occurs-in other words, when a transition-period sets in, it implies a complete reversal as regards the preceding monsoon of baric gradient, wind-direction, and other atmospheric conditions over the large area including the Arabian Sea, the Bay of Bengal, India, and Further India.

These reversals of meteorological elements occurring gradually tend to an approximate equality and uniformity of barometric pressure over a large area. This approximate uniformity of pressure over and round the coast of the Bay of Bengal, accompanied by light variable winds and calms over a considerable portion of the Bay with little or no rainfall, Mr. Eliot regards as invariable antecedents of a powerful cyclone.

\section{Connexion of Rainfall with Cyclones.}

In consequence of the small rainfall about the time of the commencements of the transition-periods, the amount of aqueous vapour in the atmosphere accumulates and gives rise to some peculiar sky-effects. When the point of saturation is attained, precipitation follows, and a heavy rainfill is con- 
centrated over a portion of the Bay, accompanied by a strong in-draught most marked from the Indian Ocean at the entrance of the Bay. Mr. Eliot regards this heavy rainfall as an immediate antecedent of a cyclone. For some years, we believe, an opinion has existed that cyclones are connected with rainfall. If our memory serves us correctly, we remember that some time in the early part of the decade $1850-60$, a work on storms was published in which the author laid some stress on the fact that cyclones mostly originate in regions characterized by active precipitation of aqueous vapour. A later writer, the Rev. Clement Ley, speaks of extensive precipitation contributing to cyclonic generation as follows :- "Extensive precipitation occurring in a region of atmosphere previously approaching a condition of tranquillity is the primary factor of every system of baric depression with its resulting atmospheric circulation, retrograde in the northern and direct in the southern hemisphere." Mr. Meldrum's Mauritius Meteorological Results for the year 1875 furnish some evidence which appears to indicate that the connexion between rainfall and cyclones is of a much stronger kind than he had before anticipated. $\mathrm{He}$ says:- " The oft-observed fact that the dry weather in Mauritius from December to April is accompanied by an absence of hurricanes in the Indian Ocean, has been repeated in 1875 . It is remarkable that, while February is generally the wettest month in Mauritius and the stormiest month in the Indian Ocean, it was in 1875 the reverse in both these respects. This seems to point to an intimate connexion between rainfall and cyclones."

Mr. Eliot, in discussing the principal facts of the Midnapore cyclone of October 1874 , found that the rainfall on that occasion was conterminous with the entire duration of the cyclone. "It is," he says, "in this case, as in others, the one meteorological factor, the introduction of which into the previously existing conditions determined the commencement of the cyclone; and the intensity and situation of the rainfall ran parallel with the intensity and position of the cyclone. The evidence which the Midnapore cyclone thus affords of the intimate connexion between rainfall and cyclone-generation is very strong, and is almost equally conclusive in favour of the condensation theory of the origin of cyclones."

\section{Connexion between Sun-spots and Cyclones.}

Mr. Eliot, in commenting on the passage above quoted from Mr. Meldrum, remarks :- " This statement of Mr. Meldrum's, when it is remembered that he has upheld the parallel-wind $\mathrm{R} 2$ 
hypothesis for the explanation of the cyclones of the southern Indian Ocean, is a very remarkable one. It may also be $e^{1+14}$ !ed, in further confirmation of it, that it affords some explanation of the connexion between cyclone-frequency, rainfall, and sunspot-frequency. Mr. Meldrum's investigations have established that the frequency and energy of cyclones in the Indian Ocean and the rainfall of the globe vary directly with the number of sun-spots, or are subject to the same law of periodicity. This relation is almost self-evident, if it be admitted that massive terrestrial atmospheric phenomena are due solely or primarily to the action of solar radiant heat, and that any niarked periodicity in the cause (solar heat and action) must impress a corresponding periodicity on the more important phenomena of the earth's atmosphere. ..... If it be granted that rainfall varies with change of the sun's photosphere, as indicated by the number of sun-spots, and that cyclones are due to rainfall, it is probable that cyclonefrequency will be subject to the same law of periodicity which affects the distribution of rainfall, and, consequently, that the occurrence of cyclones will vary with the number of sun-spots. This probable mutual connexion between phenomena apparently unconnected appears to give additional weight and force to the condensation theory."

In calling attention to severe eyclones Mr. Eliot remarks, "That severe cyclones at the head of the Bay during the month of May have generally occurred about the period of minimum sun-spots." "He also finds the same connexion characteristic of the opposite transition-period, viz. October:"The three cyclones which have occurred in the month of October during the present century, happened at or near minimum sun-spot years." He embodies the results in two general propositions as follows:-

"First. That severe cyclones, $i$. e. cyclonic storms extending over a large area and of considerable barometric depression, and therefore attended by a destructive stormwave, occur at or near the minimum sun-spot period, and that the year of minimum solar spots, or the preceding year, appears to be the most probable.

"Second. That, during the months of November and December, only ten severe cyclones have occurred during the present century ; or, taking every eleventh year as defining the minimum solar-spot period, they occurred as follows :1822 , three storms, viz. in 1822,23 , and $24 ; 1833$, three storms, viz. in 1831,32 , and $33 ; 1844$, one storm in 1842 ; 1855 , one storm in $1852 ; 1866$, one storm in $1864 ; 1877$, one storm in 1876." "Hence," Mr. Eliot says, "there is 
a strong probability of at least one severe cyclone at each minimum solar-spot period, and of its occurring in the same year, $r$ in the first or second year before the year of minimum spots."

[It is to be remarked that the three storms at the minimum period of 1822 occurred in that year and the two years succeeding it.]

Mr. Eliot proceeds :-_" It will thus be seen that the conclusions to which I have arrived are quite different from those established by Mr. Meldrum for the southern Indian Ocean. His conclusions are that cyclones in that region are most frequent and most intense at or near the maximum solar-spot periods." Mr. Eliot considers that the data are too imperfect to attempt to assign any reason for this opposite character of cyclone distribution in the Bay of Bengal and the southern Indian Ocean as referred to sun-spot periods.

For the above views, we regard $\mathrm{Mr}$. Eliot as an official authority. We have read his memoir on the Madras Cyclone, May 1877, with great interest, and consider that it embodies very valuable information on cyclones generally.

XXIX. On a new Action of the Magnet on Electric Currents. By E. H. HaLL, Fellow of the Johns Hopkins University*.

GOMETIME during the last University year, while I was $S$ reading Maxwell's 'Electricity and Magnetism' in connexion with Professor Rowland's lectures, my attention was particularly attracted by the following passage in vol. ii. p. 144:-

"It must be carefully remembered, that the mechanical force which urges a conductor carrying a current across the lines of magnetic force, acts, not on the electric current, but on the conductor which carries it. If the conductor be a rotating disk or a fluid, it will move in obedience to this force; and this motion may or may not be accompanied with a change of position of the electric current which it carries. But if the current itself be free to choose any path through a fixed solid conductor or a network of wires, then, when a constant magnetic force is made to act on the system, the path of the current through the conductors is not permanently altered, but after certain transient phenomena, called induction-currents, have subsided, the distribution of the current will be found to be the sane as if no magnetic force were in action. The only force which acts on electric

* From a separate impression from the 'American Journal of Mathematics, ${ }^{\prime}$ 1879, communicated by the Author: 